\title{
Thermo-mechanic and Microstructural Analysis of an Underwater Welding Joint
}

Pedro Hernández Gutiérrez ${ }^{1}$, Francisco Cepeda Rodríguez ${ }^{2}$, Jose Jorge Ruiz Mondragón ${ }^{1}$, Jorge Leobardo Acevedo Dávila ${ }^{1}$ Martha Patricia Guerrero Mata ${ }^{3}$, Carlos Alberto Guevara Chavez ${ }^{1}$

1 Corporación Mexicana de Investigación en Materiales, Gerencia de Desarrollo Tecnológico, Saltillo, Coahuila México.

2 Universidad Autónoma de Coahuila - UAdeC, Facultad de Ingeniería Mecánica y Civil, Arteaga, Coahuila México.

3 Universidad Autónoma de Nuevo León - UANL, Facultad de Ingeniería Mecánica y Eléctrica, San Nicolás de los Garza, NL, México.

Received: 02 Feb., 2016

Accepted: 25 Apr., 2016

E-mail: welding_support@icloud.com (PHG)

\begin{abstract}
The aim of this research is to present a comparative analysis between theoretical and experimental thermal fields as well as a microstructural behaviour and residual stresses applying multiple weld beads in the joint of two API $5 \mathrm{~L}$ X52 pipe sections. The thermal field, microstructural and residual stresses were numerically modelled through the finite element method (FEM) and compared to experimentally. The simulation conditions used in the FEM analysis were similar considerations to the underwater welding conditions. The finite element analysis was carried out, first by a non-linear transient thermal analysis for obtaining the global temperature history generated during the underwater welding process. Subsequently, a microstructural behaviour was determined using the temperatures distribution obtained in the pipe material by calculating the structural transformations of the material during the welding process, and finally a stress analysis was developed using the temperatures obtained from the thermal analysis. It was found that this simulation method can be used efficiently to determinate with accuracy the optimum welding parameters of this kind of weld applications.
\end{abstract}

Key-words: API 5L X52; Finite element analysis; Residual stresses; Temperature field; Underwater welding.

\section{Análise Termo-mecânica e Microestrutural da União Soldada Durante Soldagem Subaquática}

Resumo: O objetivo deste trabalho é apresentar uma análise comparativa entre os campos térmicos teóricos e experimentais, bem como um comportamento microestrutural e as tensões residuais aplicando cordões em solda multipasses na união de duas seções de tubo API 5L X52. O campo térmico, as microestruturas e as tensões residuais foram numericamente modelados através do método por elementos finitos e comparados com o experimental. As condições de simulação utilizadas na análise por elementos finitos foram consideradas semelhantes às condições de soldagem subaquáticas. A análise por elementos finitos foi efetuada, primeiramente uma análise térmica transiente não linear para obter a evolução da temperatura global gerada durante a soldagem subaquática. Depois, um comportamento microestrutural foi determinado usando a distribuição de temperaturas obtida no material do tubo calculando as transformações estruturais do material no processo, e, finalmente, uma análise de tensões foi desenvolvida utilizando as temperaturas obtidas a partir da análise térmica. Foi encontrado que este método pode ser utilizado eficientemente para determinar com precisão os parâmetros de soldagem ótimos neste tipo de soldagem por simulação.

Palavras-chave: API 5L X52; Análise de elementos finitos; Tensões residuais; Campo de temperatura; Soldagem subaquática.

\section{Introduction}

The continuous demand of petroleum around the world, and the extraction of it, in offshore deposits that was considered unprofitable, now has been carried out. Likewise the infrastructure that is used and required for this propose, should be repaired and maintained. Therefore, the development of underwater wet weld takes an important role, this is because it offers advantages to repair structures that require reinforcements to comply with a strict structural performance and also an evaluation of a joint to comply with an established welding codes. 
In welds that are made in underwater environment, the thermo-mechanical phenomena is associated and closely related, to the heat generated during the arc transfer to the work piece, the heat transfer between base metal and transfer metal, phase transformations and the heat exchange between the welded joint and the environment. The elevated temperature gradients that are present on the welding zone during both, the heating and the cooling process, decrease the mechanical properties, and also yield to nonhomogeneous permanent strains and residual stresses on the involved materials. The final result is a permanent distortions in the welded parts.

Goldak et al. [1], were made the first research that introduce a double ellipsoidal moving heat source and used finite element method (FEM) to analyse the thermal history. Their results showed that a 3D heat source could overcome the limitations that have the previous 2D Gaussian model to predict the temperature of the welded joints with deeper weld penetration. Zhu and Chao [2] studied the thermal transient temperature effects on the material properties, residual stresses and distortion. Also they found, that during a multi-pass welding process, the thermal fields are both, non-uniform and transient. Likewise, in their results, the temperature field behaviour directly affect the residual stresses, though the thermal stresses, and indirectly as well, cause the thermal stresses come together with phase and microstructure changes. Senchenkov et al. [3] developed a FEM model for study the residual stress, distortions and microstructure on the weld of steel cylinders; they were obtained numerical results that had a good correlation with experimental results. However, these authors conclude that when the weld have subsequent welds, the numerical results of model shows a small discrepancy in the microstructure phase. This discrepancy was attributed, because the model do not consider the martensitic and austenitic phases interaction. Finally Villalobos et al. [4] have tested that it is viable to simulate by FEM analysis a welding assembly with a controlled multi-pass sequence, nevertheless their research do not have a complete multiphysics analysis (microstructure, mechanical and thermal), and also it is not considered the sequential influence of a multiple weld applications on the assembly.

These influence of the thermal fields should be assessed as they are interesting in terms of material and technology designing. Likewise the prediction of the mechanical behaviour of underwater welded joints has not yet been fully resolved, since inconsistency is present in the different models that are developed.

The aim of this work is to investigate the effects that are produced by a underwater multi-pass MMAW welding process, on the thermo-mechanical behaviour, microstructural phase transformation, thermal stress and distortions, in a two welded pipe sections of API $5 \mathrm{~L}$ material.

\section{Experimental Details and FEM Considerations}

\subsection{Experimental welding conditions}

For the experimental welding procedure, it was used a plate sections of API $5 \mathrm{~L}$ X52 pipe with $11 \times 10^{-3} \mathrm{~m}$ of thickness, the angle of the " $\mathrm{V}$ " bezel was at $45^{\circ}$, and was applied on a pipe sections of $17 \times 10^{-2} \times 40 \times 10^{-2} \mathrm{~m}$. The application was made without back support and $1.5 \times 10^{-3} \mathrm{~m}$ of root open. An $\mathrm{E} 7024$ rutilic commercial electrode with a $5 \times 10^{-3} \mathrm{~m}$ diameter and $35 \times 10^{-2} \mathrm{~m}$ in length was used, the process simulation was made by FEM.

The multi-pass welding was used due the thickness of the samples. It was necessary to maintain the same welding parameters between the multi-pass steps. The welding current intensity was $\mathrm{I}_{\mathrm{s}} 210 \mathrm{~A}$, the arc welding voltage $U_{a}=25 \mathrm{~V}$, the welding speed $V_{e}=2.54 \times 10^{-3} \mathrm{~m} / \mathrm{s}$. and therefore the heat input $\mathrm{Ei}=207 \times 10^{4} \mathrm{~J} / \mathrm{m}$.

The welding joint was made by a MMAW process. The micro and macrostructure characterization of the welded coupons were achieved through a transversal cut in the welding zone. Finally the residual stress efforts were evaluated with an X-ray diffraction (DRX) method, using an X-ray equipment model: X Xtress 3000, sustained in the angular measurement of deformations distribution in the materials structure, based on Hook's law. The welding conditions are showed on Table 1.

\subsection{Numerical FEM assumption and boundary condition and analysis of temperature}

For the numerical model prediction, and in order to obtain analytical solutions of differential equation of heat conduction, the following assumption and boundary condition were adopted. 
Table 1. Parameters used on each coupon to characterization by DRX.

\begin{tabular}{lcc}
\hline \multicolumn{1}{c}{ Parameter } & Value & Unit \\
Radiation & CrKa & $156.4^{\circ}$ \\
Collimator open size & $1 \times 10^{-3}$ & $\mathrm{~m}$ \\
Measure frequency & $3 \times 10^{-3}$ & $\mathrm{~m}$ \\
Collimator distance & $9.75 \times 10^{-3}$ & $\mathrm{~m}$ \\
Direction & $90^{\circ}$ & $\mathrm{V}$ \\
Voltage & 30000 & $\mathrm{~A}$ \\
Current & $5 \times 10^{-3}$ & $\mathrm{MPa}$ \\
Young module & 211000 & $\mathrm{~m}$ \\
Poisson relation & 0.3 & $1.3 \times 10^{-3}$ \\
Distance from surface & & \\
\hline
\end{tabular}

I. The base material is isotropic and the physical properties of the API $5 \mathrm{~L}$ depend on the temperature, $\mathrm{k}$ and $\lambda$ are independent on the temperature;

II. The heat input are constant;

III. Heat losses from surface by radiation are not considerate;

IV. The heat losses into the environment, due to convection, are take into account;

V. The influence of the latent heat at melting and solidification is negligible;

VI. The t8/5 was 2.5 seconds (function of Heat Input [5]).

During the analysis, the variation of the temperatures as a function of time, and the expansion of the heat affected zone (HAZ) were monitored for a butt welded joint. For the analysis of the temperatures distribution, the source was considered to be doubled ellipsoidal. The double ellipsoidal heat source compromises on two different volumetric power sources of the same geometrical shapes but with a dissimilar dimensions. The two different components of the model define the front and the rear of the heat source, respectively. The mathematical equation that describes the front of the heat source models its steep shape resulting from the movement of the heat source. Meanwhile the equation that describes the rear of the heat source is adapted to the smooth gradients of the heat flux. In conclusion, two different semi-ellipsoids are combined to give the heat source, while the heat flux within each ellipsoid is described by Equations 1 and 2. For a point $(x, y, z)$ within the first semi-ellipsoid located in the front of the welding arc, the heat flux equation can be written as follows:

$$
Q(x, y, z)=\frac{6 \sqrt{ } 3 r_{f} Q}{a_{h} b_{h} c_{h f} \pi \sqrt{ } \pi} e^{-3 x^{2} / a_{h}} e^{-3 y^{2} / b_{h}} e^{-3 z^{2} / c_{h f}}
$$

While, for a point located in the second semi-ellipsoid, covering the rear section of the arc, the heat flux is described as:

$$
Q(x, y, z)=\frac{6 \sqrt{ } 3 r_{b} Q}{a_{h} b_{h} c_{h r} \pi \sqrt{ } \pi} e^{-3 x^{2} / a_{h}} e^{-3 y^{2} / b_{h}} e^{-3 z^{2} / c_{h r}}
$$

where $a_{h}, b_{h}, c_{h f}$ and $c_{h b}$ are the ellipsoidal heat source geometric parameters, shown in Figure $1, Q$ is the arc heat input, which includes the factor of arc efficiency, $\eta=0.58$ for MMAW, in equation: $Q=V \cdot l \cdot c$. The parameters $r_{f}$ and $r_{b}$ are proportion coefficients representing heat apportionment in front and back of the heat source, respectively, where $r_{f}=r_{b}=2$. It is of great importance to note that, due to the condition of continuity of the overall volumetric heat source, the values of $Q(x, y, z)$ given by Equations 1 and 2 must be equal at the $X=0$ plane. From this condition, another constraint is obtained for $r_{f}$ and $r_{b}$, namely that $r_{f} / C_{h f}=r_{b} / C_{h b}$. Subsequently, the values for these two coefficients are determined by Equation 3: 


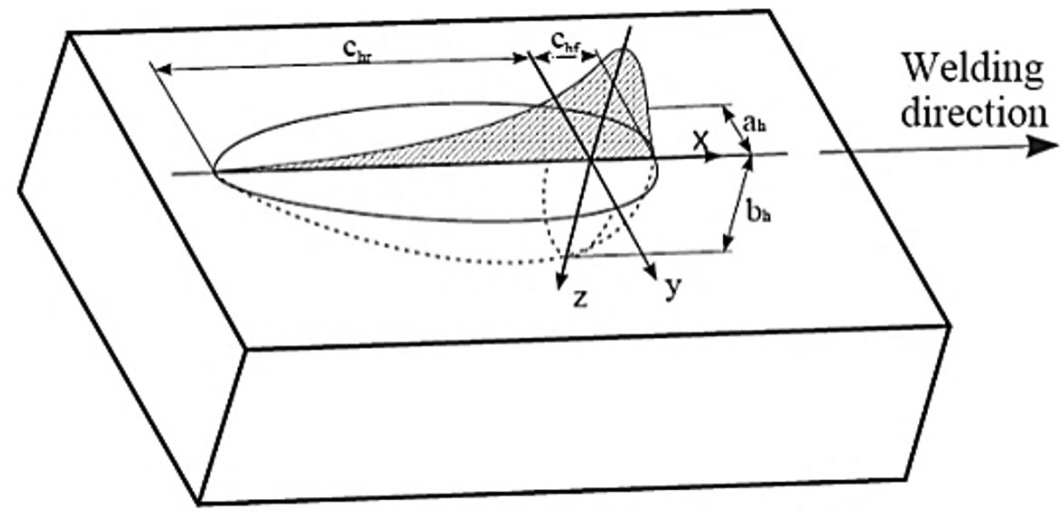

Figure 1. Geometric parameters of Goldak's double ellipsoidal heat source model [6].

$$
\begin{aligned}
& r_{f}=2 c_{h f} /\left(c_{h f}+c_{h b}\right) \\
& r_{b}=2 c_{h b} /\left(c_{h f}+c_{h b}\right)
\end{aligned}
$$

The parameters $a_{h}, b_{h}, c_{h f}$ and $c_{h b}$ are related to the characteristics of the welding arc.

The three-dimensional FEM contained a total of 8,577 nodes associated with 7,698 eight-node isoparametric solid elements. Due to expected high temperatures and stress a gradient near the weld and the geometry is complex, a relatively fine mesh is used in the welding area. Element size increases progressively with distance from the weldment.

The dependence of the properties of the base metal subjected to electric arc welding are considered to the temperature, the phase composition of the API $5 \mathrm{~L}$ and the released or absorbed therein as a result of the phase transformation.

\subsection{Phase transformation}

To numerically calculate the kinetics of the phase transformations of the base metal subjected to electric arc welding during the current increment, a numerical base model based on the approximation of the thermokinetic of isothermal diagrams of formation or decomposition of the overcooled austenite was proposed in [7].

The initial data used of the isothermal diagrams are as follows:

a) An isothermal diagram in the forms of lines of the beginning and of transformations;

b) The ultimate fraction of the phase being calculated;

c) The temperature dependence of the hardness of the phase being calculated.

The method on the determination of a metallurgical analysis is based on phase transformation laws [8], likewise is performed to simulate the phase transformation during welding. When a base metal is heated above $\mathrm{A} 1$ (cementite disappearance temperature) temperature, pearlite-ferrite partly transforms into austenite, and when the temperature is higher than A3 (a-ferrite disappearance temperature), pearlite-ferrite completely changes into austenite. For carbon steel and low alloy steel, the A1 and A3 temperatures can be calculated according to the following empirical Equations 4 and 5 respectively [9]:

$$
A_{1}=723-10.7 \mathrm{Mn}-16.9 \mathrm{Ni}+29 \mathrm{Si}+16.9 \mathrm{Cr}+290 \mathrm{As}+6.4 \mathrm{~W}
$$




$$
\begin{aligned}
& \mathrm{A}_{3}=912-203 \sqrt{\mathrm{C}}-15.2 \mathrm{Ni}+44.7 \mathrm{Si}+104 \mathrm{~V}+ \\
& 31.5 \mathrm{Mo}+13.1 \mathrm{~W}+30 \mathrm{Mn}-11 \mathrm{Cr}-20 \mathrm{Cu}+700 \mathrm{P}+400 \mathrm{Al}+120 \mathrm{As}+400 T i
\end{aligned}
$$

In this research, the peak temperature that can be reached for an integration point of an element during heating process and the cooling time it was assumed to be $(\mathrm{t} 8 / 5)$ from $500^{\circ} \mathrm{C}$ to $800^{\circ} \mathrm{C}$, this decision was taken whether the point underwent the martensitic transformation. Likewise, from the continuous cooling transformation diagram $(C C T)$, the relationship between the cooling rate and the fraction of the martensite can be obtained.

\subsection{Weld thermal analysis}

The obtained results in the numerical FEM analysis are shown in Figure 2A. It can be seen the thermal history and the maximum generated temperatures in the welding zone, and his surround areas, during the multi-pass MMAW process. The Figure 2B shows the obtained aspect ratio of the welding area obtained experimentally in a macrograph. The macrograph of the Figure $2 \mathrm{~B}$, shows a transversal cut in the welding area of the API $5 \mathrm{~L}$ steel. The results obtained by the FEM and experimental were compared. It was found a satisfactory correlation, since the molten zone size in both cases shows a highly similitude and the HAZ limits from Figure 2B, match with the observed temperatures in the range between $886-1098^{\circ} \mathrm{C}$ (green and orange bands) on Figure $2 \mathrm{~A}$. Similar experimental results were achieved by Kelly and Joseph [10] and Babu [11], their research agree that the austenization temperature range, that generally entails to recrystallization and grain refinement is reached at similar temperatures.

\subsection{Mechanical analysis of multi-pass weld}

The Figure 3 shows a comparison of the microhardness profile behaviour predicted by the numerical FEM simulation and the experimental results at $5 \mathrm{~mm}$ under surface of base material (Figure $3 \mathrm{~A}$ ), and on the bottom of the weld area (Figure 3B). It can be seen in boot figures that the mechanical history of the maximum hardness generated in the welding zones and surround areas during multi-pass welding MMAW process have

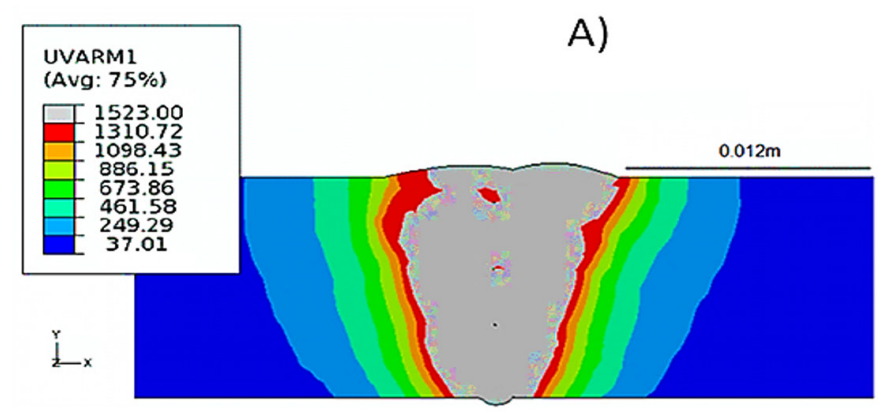

B)

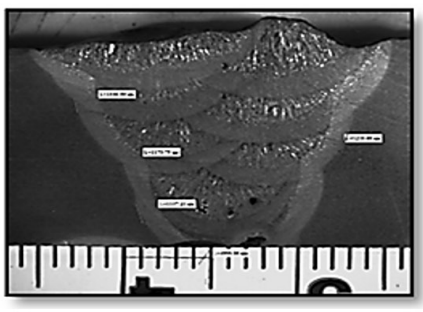

Figure 2. (A) FEM thermal analyses, (B) Welding zone transversal macrograph.
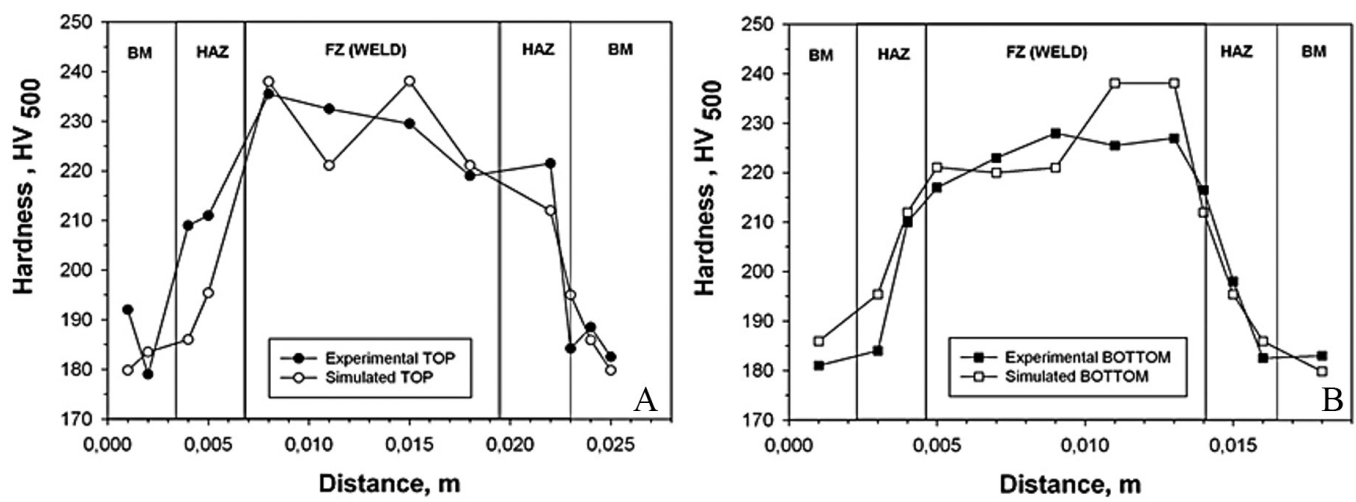

Figure 3. The results of transversal zone microhardness of the (A) FEM simulation, (B) Experimental samples. 
high degree of similarity. The Figure 3A shows the results obtained near to the top of the welding profile, the model FEM predicted a microhardness profile made with the welding parameters and boundary conditions that are listed on above. The hardness experimental profiles and the hardness predicted in the HAZ zone by the FEM numerical model show a good correlation in magnitude, it was found that microhardness behaviour in this zone is the range of 195 to $221 \mathrm{HV}(500 \mathrm{~g})$. Babu [11] found that for this hardness the critical temperatures is ranging between 500 and $800^{\circ} \mathrm{C}$. According to the Institute International of Welding [12] the cooling rate is estimated by the coefficient of $\mathrm{t} 8 / 5$ that is the dwell time in this range of temperature. It was found a closely difference between the experimental and predicted of the numerical FEM model hardness results.

\subsection{Microstructural analysis}

The Figure 4A to the Figure 4C shows the FEM and experimental microstructural results. The values obtained of the FEM analysis shows the saturation percentage of phase present, predicted by the numerical model at the welding zone, it can be seen that three phases were found at the microstructure: Ferrite, Allotriomorphic Ferrite and Widmanstätten Ferrite. Also the Figure 4A to 4C shows the experimental results. The micrographs were obtained at the transversal section of the welded zone, aimed for validate the FEM model.

It can be seen in Figure 4, that the numerical FEM analysis shows the phase saturation analysis goes from $100 \%$ (red) to $0 \%$ (blue). Figure 4A shows the ferrite phase, the Figure 4B, the Allotriomorphic phase and Figure 4C, the Widmanstätten phase. Likewise the results were validated with a micrograph in weld area at 500x, doing a comparison between the phase founded on the microstructure and the FEM model predict results.

Unlike the thermal model, the microstructural validation have a higher complexity level because, there are not an accurate tools to realize the present phases percentage quantification at micrograph, however in the zones were FEM model predict more saturation of any phase, the micrograph shows similar results. Figure $4 \mathrm{~A}$, simulation
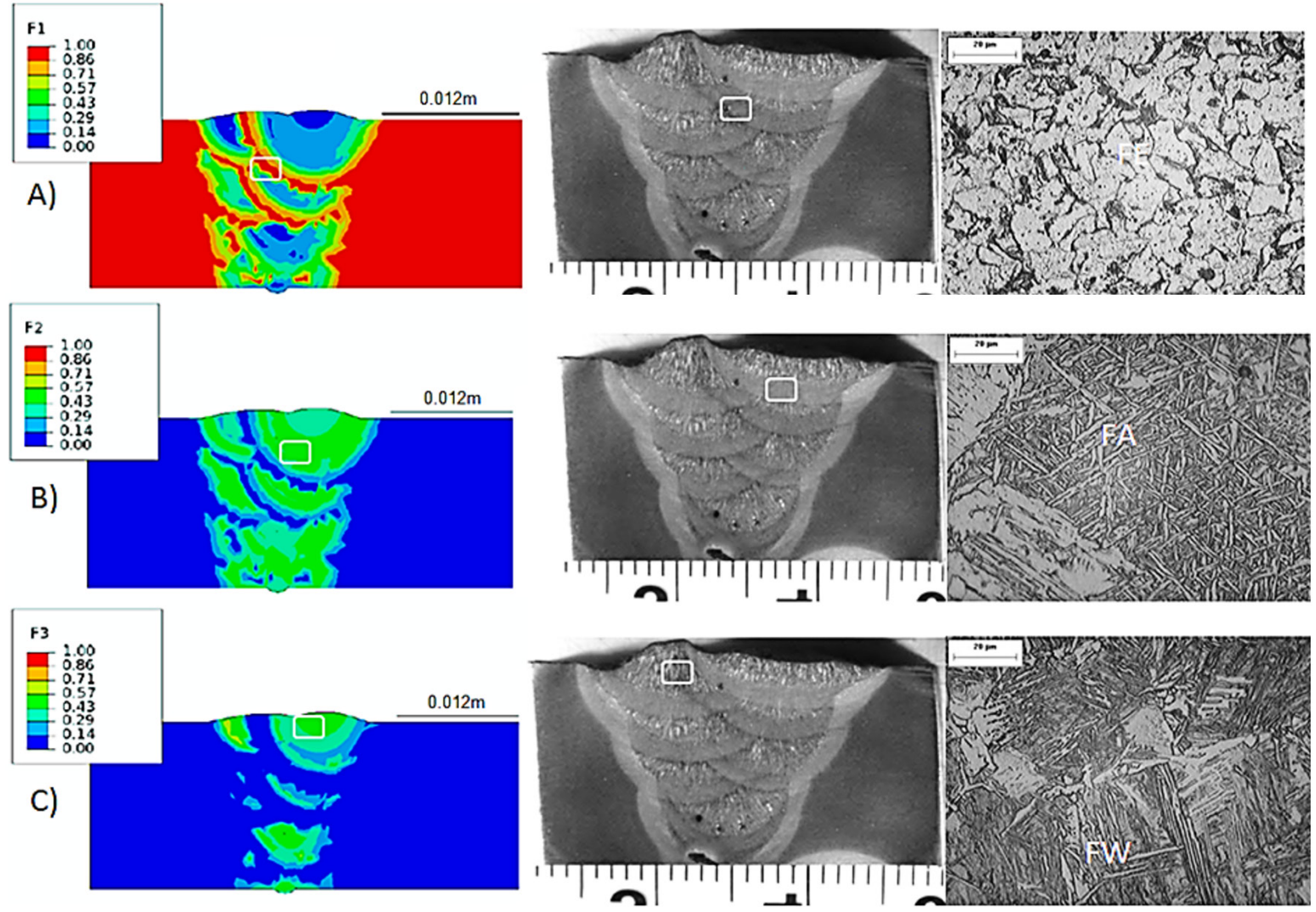

Figure 4. Present phase's percentage in welding zone coupons and experimental micrograph at 500X. (A) Ferrite Phase (FE), (B) Allotriomorphic Ferrite (FA), and (C) Widmanstätten Ferrite (FW). 
can be seen that the model predict a ferrite concentration at the interphase zone of the welds. The ferrite is easily identified in Figure 4A (clear phase), likewise in Figure 4B macrograph, it can be seen the formation of thin ferrite plates that are named Allotriomorphic Ferrite. The Allotriomorphic Ferrite is formed on the beginning of the weld solidification, from austenitic boundary grain, under Ae3 temperature [13]. It can be seen on Figure $4 \mathrm{C}$ that in several weld zones the grain growth has a needle, which is not a result of phase transformation by a displacement, rather it is caused by a metastable mechanism with fast diffusion of carbon through the interphase of the retained austenite which caused a shear transformation. The shear transformation trough the interphase of retained austenite is a characteristic of Ferrite Widmanstätten growth [11].

Likewise on the macrographs of Figure $4 \mathrm{~A}$ to $4 \mathrm{C}$, it can be seen some areas with a porosity concentration around the welding zone. The main cause of the porosity is that during underwater welding, the liquid metal from the electrode is covered with molten slag in order to form droplets. As a droplet forms at the tip of the electrode, hydrogen, the main gas ingredient found in droplets, according to the literature [5,14], and the hydrogen could diffuse into the droplet and form internal porosity. Therefore, gas is transported in the liquid metal droplets and incorporated to the weld metal, part of this gas escapes from the weld and the other part is trapped forming the weld metal porosity.

\subsection{Residual stresses analysis and thermic distortions of multi-pass weld}

The residual stresses in welded structures in environment wet are generated through the thermal stresses which are present during MMAW, the expansion and contraction of the metal during heating and cooling, respectively, of the thermal cycle are responsible for the material to be plastically deformed. At the end of the thermal cycle a residual stress field is formed resulted from the plastic behaviour of the material, which is apparent in the microstructure due to an increase in dislocation density. To numerical corroborate the stress analysis model and thermal distortions produced in the welded joint, it was necessary to structurally analyse these phenomena by using FEM. The thermal field modelling was taken into account, considering the temperature distribution as loads for the time intervals in question. The base metal characteristic: as longitudinal modulus of elasticity, modulus of elasticity in shear, thermal conductibility, Poisson's number and flow limit were introduced in the first stage as invariable entry data, in the second stage, as data depending on temperature.

In Figure 5 shown high variations of the stress at the longitudinal and transverse directions. In both directions during welding, two experimental profiles were measured by the X-ray stress, in order to corroborate the results by the FEM model. In the longitudinal direction is shown a positive stress is apparent which demonstrates the
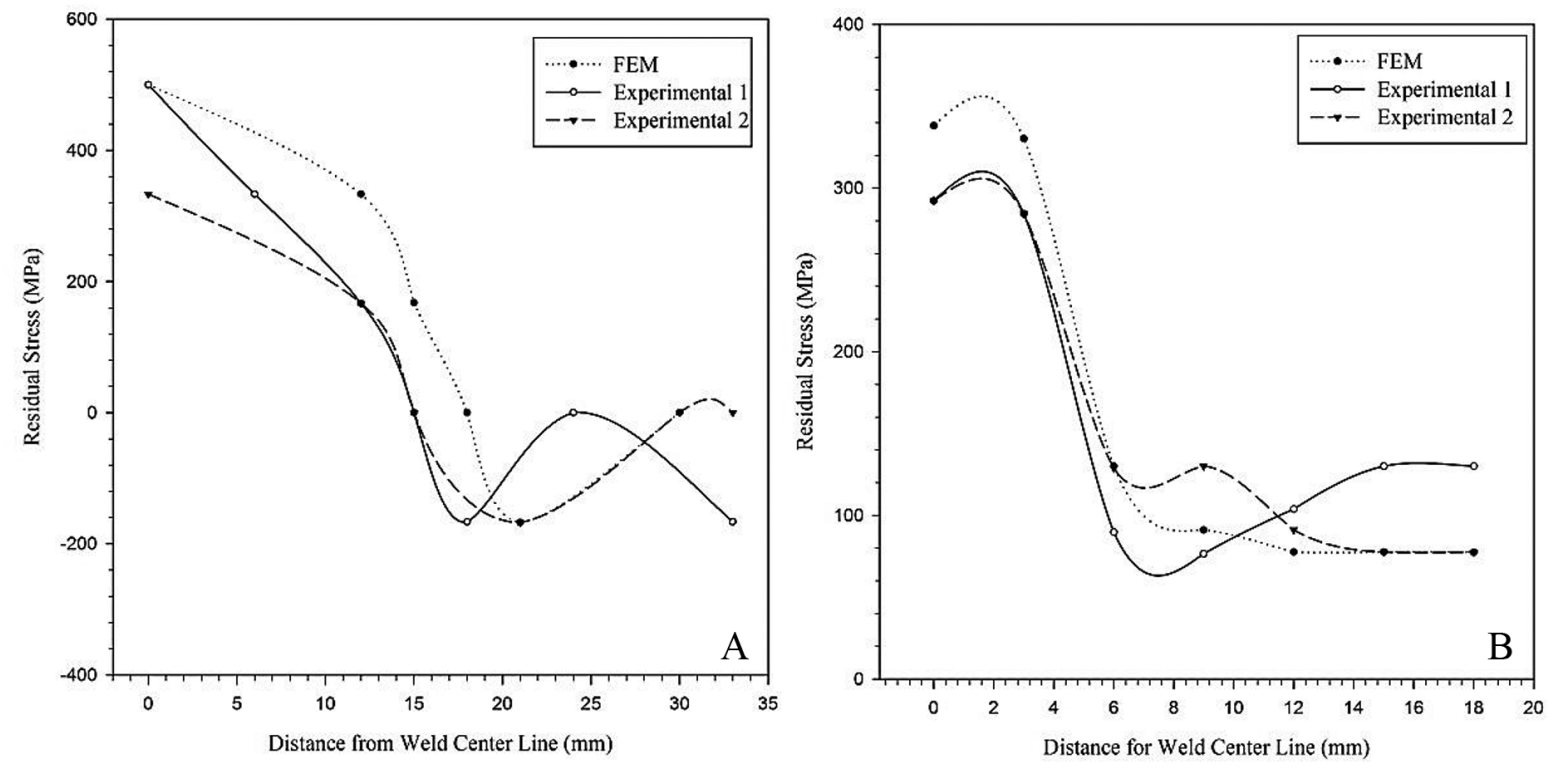

Figure 5. Comparison of $\mathrm{X}$-ray residual stress measurement and finite element predictions; $(\mathrm{A})$ longitudinal residual Stress (left); (B) Transversal residual stress (right). 
rapid change of expansion-contraction of the metal during heating-cooling in environment wet presented high stress concentration in the order of 380-500MPa. The longitudinal stresses are of tensile and compression type, located under the $X$ axis, which starts once the welded joint start cooling and levelling the stresses in the final stage due to structure relaxation, and it also balances the internal stresses.

Through carefully comparing the experimental results and the simulated results it can find that the simulated results are closer to the experimental results of both cases.

The predicted and measured transverse residual stresses in the initial weld (see Figure 5B) are of low magnitude relative to the peak longitudinal stresses. The overall agreement between the predicted and measured results is evident. The cross-section model predicted that multi-pass weld significantly increased the transverse residual stresses. However, it is worth noting here that the measured transverse residual stresses tend to be lowest than the predicted values, but with an overall trend being consistent with the predicted one.

Apart from residual stresses the inhomogeneous heat distribution in the metal during welding leads to temporal or permanent deformation (displacements and rotations). The liquation of the weld pool, along with the upcoming solidification and the thermal expansion of the metal are the main mechanisms that drive deformation. Stress and deformation are largely opposed [15]. High stresses occur where deformation is restrained and low stresses occur where deformation is unrestrained and reversely.

After the welding two dimensional were measured, the changes are defined based on the direction of their gradient to the weld line and listed as:

- Angular change that consist of a rotation around the weld line.

- Transverse shrinkage that occurs perpendicular to the weld line.

The values of thermal distortions were compared between the values of the distortion obtained in simulation and measuring two macrographic experimental samples. The results are shown in Table 2.

Table 2. Measures distortion angular and displacement transversal for two manual metal arc multi-passes weld deposits.

\begin{tabular}{lcccc}
\hline & $\begin{array}{c}\text { Distortion } \\
\text { angular }(\mathbf{a})\end{array}$ & $\begin{array}{c}\text { Distortion } \\
\text { angular }(\boldsymbol{\beta})\end{array}$ & $\begin{array}{c}\text { Displacement Transversal (mm)* } \\
\text { Left }\end{array}$ \\
Experimental 1 & 1.32 & 1.29 & 0.12 & 0.35 \\
Experimental 2 & 1.30 & 1.28 & 0.17 & 0.41 \\
FEM & 1.27 & 1.26 & -0.04 & 0.58 \\
\hline
\end{tabular}

*Positive and negative displacements indicates shrinkage and expansion, respectively.

Is observed that a similitude between thermal distortion values obtained at the FEM simulation and experimental coupons, both ends are distorted proportionally because the effort distribution during solidification. The angular change of the weld joint has been apparent in the as-welded case and it has also been predicted by the numerical model. With respect to the transverse displacement values obtained (right side) are similar in both cases, to the transverse displacement (left side); the model shows a small discrepancy resulting in an expansion of $-0.04 \mathrm{~mm}$ regarding the contraction found in coupons welding.

In this manner the simulation shows similar results to the obtained in experimentation

\section{Conclusions}

Derivative of this research, the follow conclusions are obtained:

The FEM analysis is an adequate method to predict the thermal, mechanical and microstructural behaviour in multi-pass weld joints, which undoubtedly represent an analysis time diminution compared with a statistic experimental study. 
Numerical modelling of the thermal field using the FEM is a commonly used method which, by its results, gives distribution to the thermal field and the values of temperatures close to those experimentally measured.

Is possible to reproduce by FEM the temperature fields (thermal simulation) in welds through comparison of them with the edges of fused zone and HAZ obtained from welding coupon.

The thermal cycles during a MMAW multi-pass welding process produce a more complex distribution and multi microstructural phases compared with a single welding bead, this because the subsequent weld bead applications.

With the used weld deposit sequence (FEM and experimental) was obtained acceptable residual stress, mechanical, microstructural and thermomechanical distortion at weld coupon, therefore this sequence can be used to weld components in underwater welding.

\section{Acknowledgements}

The authors wants to acknowledge the Consejo Nacional de Ciencia y Tecnología (CONACYT), Fondo Institucional de Fomento Regional para el Desarrollo Científico, Tecnológico y de Innovación (FORDECyT) en el Desarrollo de Capacidades en Soldaduras Aplicadas en Ambientes Marinos for the economic support to realize this study, likewise to the microstructural analysis laboratory personnel from Corporación Mexicana de Investigación de Materiales and the Universidad Autónoma de Nuevo León, Facultad de Ingeniería Mecánica y Eléctrica for the support during the analysis of the weld coupons.

\section{References}

[1] Goldak J, Chakravarti A, Bibby M. A double ellipsiod finite element model for welding heat source. Abington: International Institute of Welding; 1985.

[2] Zhu XK, Chao YJ. Effects of temperature-dependent material properties on welding simulation. Computers \& Structures. 2002;80(11):967-976. http://dx.doi.org/10.1016/S00457949(02)00040-8.

[3] Senchenkov IK, Zhuk YA, Chervinko OP, Turyk E. Modelling of residual stresses developed in steel cylinders subjected to surface-layer deposition by welding. Journal of Engineering Mathematics. 2008;61(2-4):271-284. http://dx.doi.org/10.1007/ s10665-007-9209-8.

[4] Villalobos D, Maldonado C, Albiter A, Robles-Piedras E. Effect of thermal cycles on the HAZ of a stainless steel multipass weld of superduplex SAF 2507. Soldagem \& Inspeção. 2010;15(3):170176. http://dx.doi.org/10.1590/S0104-92242010000300002.

[5] Anik S, Dorn L. Schweisseignung mettalischer Werkstoffe. Düsseldorf: Dt. Verlag für Schweisstechnik, DVS-Verlag; 1995.

[6] Nguyen NT, Ohta, A, Matsuoka K, Suzuki N, Maeda, Y. Analytical solutions for transient temperature of semi-infinite body subjected to 3-D moving heat sources. Welding Research Supplement. 1999:266s-274s.

[7] Popov AA, Popov LE. Isothermal and thermokinetic diagrams of the decomposition of supercooled austenite: Heat-Treater's Handbook Metallurgiy. Moscow: Mashgiz; 1965.
[8] Kosistinen DP, Marburger RE. A general equation prescribing extent of austenite-martensite transformation in pure $\mathrm{Fe}-\mathrm{C}$ alloys and plain carbon steel. Acta Metallurgica. 1959;7:50-60.

[9] Watt DF, Coon L, Bibby M, Goldak J, Henwood C. An algorithm for modelling microstructural development in weld heataffected zones, (part A) reaction kinetics. Acta Metallurgica. 1988;36(11):3029-3035. http://dx.doi.org/10.1016/00016160(88)90185-X.

[10] Kelly F, Joseph R. Welding, brazing and soldering. 10th ed. Materials Park, OH: ASM International; 1993. 1155 p. (ASM Handbook, vol. 6,).

[11] Babu SS. The mechanism of acicular ferrite in weld deposits. Current Opinion in Solid State and Materials Science. 2004;8(34):267-278. http://dx.doi.org/10.1016/j.cossms.2004.10.001.

[12] International Institute of Welding. Guide to the metallurgy of welding and weldability of low carbon microalloyed hot rolled steels. Abington: International Institute of Welding; 1987.

[13] Lorenz K, Düren C. Evaluation of large diameter pipe steel weldability by means of the carbon equivalent. Duisburg: Mannesmann-Forschungsinst; 1982.

[14] Perez F, Liu S. The mechanism of porosity formation in underwater wet welds: Session 9: defect analysis \& mitigation. In: AWS International Congress; 2006 October 31-November 2; Atlanta, Georgia. Miami: American Welding Society; 2006. p. 215-218.

[15] Radaj D. Heat effects of welding: temperature field residual stress distortion. Berling: Springer-Verlag; 1992. 